\title{
Source water odor in one reservoir in hot and humid areas of southern China: occurrence, diagnosis and possible mitigation measures
}

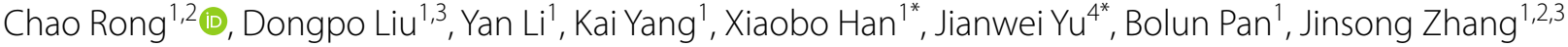 \\ and Min Yang ${ }^{4}$
}

\begin{abstract}
Background: Identifying typical odor-causing compounds is essential for odor problem control in drinking water. In this study, aiming at a major water source reservoir in hot and humid areas in southern China, which encountered seasonable odor problems in recent years, an integrated approach including comprehensive two-dimensional gas chromatography with time-of-flight mass spectrometry (GC $\times$ GC-TOFMS), flavor profile analysis (FPA) and quantitative real-time polymerase chain reaction ( $(\mathrm{PPCR})$ was adopted to investigate the odor occurrence.

Results: The results indicated that earthy-musty odor is blamed to the seasonable odor problems, and it is consistent with the complaints results from consumers. Fifty-four typical odor compounds were investigated in the reservoir and twelve were detected, of which, 2-methylisoborneol (2-MIB) was significantly increased during the odor event. Pseudanabaena sp. is the dominant species in the reservoir, which can be further represented by the number of mic gene with $\mathrm{qPCR}$ method $\left(R^{2}=0.746, P<0.001\right)$. Oxygen consumption $\left(C O D_{M n}\right)$ and dissolved organic carbon (DOC) have great influence on growth of Pseudanabaena sp., and the release of 2-MIB from the Pseudanabaena sp. cells is affected by temperature and light.

Conclusion: Our findings demonstrated that 2-MIB is the odor-caused substance in the reservoir and Pseudanabaena sp. is the main 2-MIB producer, which was confirmed as a benthic filamentous algae. Due to $C O D_{M n}$ and DOC have great influence on Pseudanabaena sp. growth, further measures to reduce the CODMn and DOC input should be performed. We also demonstrated that the 2-MIB release is affected by temperature and light. The risk of sudden increase of 2-MIB will be reduced by raising the depth of water in the reservoir. Our study will improve the understanding of T\&O problems in this city, as well as in other hot and humid area.
\end{abstract}

Keywords: Drinking water, Earthy-musty odor, Pseudanabaena sp., 2-MIB, qPCR

\footnotetext{
*Correspondence: xiaobohan7@qq.com; jwyu@rcees.ac.cn

${ }^{1}$ Shenzhen Water Affairs (Group) Co., Ltd., Water Building, 1019 Shennan Middle Road, Futian District, Shenzhen, Guangdong, China

${ }^{4}$ Key Laboratory of Drinking Water Science and Technology, Research Center for Eco-Environmental Sciences, Chinese Academy of Sciences, 18 Shuang Qing Road, Haidian District, Beijing, China

Full list of author information is available at the end of the article
}

\section{Springer Open}

(c) The Author(s) 2018. This article is distributed under the terms of the Creative Commons Attribution 4.0 International License (http://creativecommons.org/licenses/by/4.0/), which permits unrestricted use, distribution, and reproduction in any medium, provided you give appropriate credit to the original author(s) and the source, provide a link to the Creative Commons license, and indicate if changes were made. 


\section{Background}

Taste and odor $(\mathrm{T} \& \mathrm{O})$ are an important esthetic index to indicate the quality of drinking water and it is a direct hint for users to judge the drinking water whether is safe [1]. Although no researches have shown that the presence of some odorants in the drinking water will cause harm to human health [2-4], the unpleasant smell of drinking water will undoubtedly affect the quality of consumers' life and the impression of water supply enterprise [5].

Even T\&O problem occurrence was widely reported worldwide [4-6], identification of odor causing compounds is still a big challenge. Moreover, due to the low odor threshold concentration (OTC) of the odorants, for instance, 2-MIB (2-methylisoborneol) and geosmin were reported as $10 \mathrm{ng} / \mathrm{L}$ and $8 \mathrm{ng} / \mathrm{L}$, respectively [7], and the limited removal efficiency with conventional water treatment process $[8,9]$, it is difficult for water treatment plant to adopt applicable control measures once encountering $\mathrm{T} \& \mathrm{O}$ episodes in drinking water. For reservoir or lake source water, most $\mathrm{T} \& \mathrm{O}$ occurrence has been linked to some cyanobacterial metabolites such as 2-MIB and geosmin; however, there are still some other possible odorants existence responsible for odor occurrence [10, 11]. Thus, it is one prerequisite to identify possible odorants for further choosing effective control measures.

Gas chromatography and mass spectrometry (GC/ MS) have been widely adopted for odorant quantification in water, such as 2-MIB and geosmin [7]. However, due to its limited separation and resolution, it is difficult for odorant qualification. Previous studies have reported that the comprehensive two-dimensional gas chromatography with time-of-flight mass spectrometry $(\mathrm{GC} \times \mathrm{GC}-\mathrm{TOFMS})$ has higher resolution, sensitivity and separation, and it was considered suitable for the analysis of highly complex samples [12]. GC $\times$ GCTOFMS method has more applications in the field of food and chemical industries [13], while having limited use in environment. By combining odor characteristic evaluation, GC $\times \mathrm{GC}-\mathrm{TOFMS}$ has been applied for odorant screening and identification in complex aquatic environment [14].

Because the algae growth, synthesis and release of odorants in algae cells are affected by environmental factors such as water temperature, precipitation, light, and nutrients [15-17], identifying the odorant-producing algae and finding the key environmental affecting factors can reduce the risk of $\mathrm{T} \& \mathrm{O}$ outbreaks from the source. $\mathrm{Su}$ et al. [18] indicated that the risk for T\&O could be reduced by increasing the water level in Miyun reservoir (2.91\% reduced for each meter increase). However, it should be noted that this process is difficult since there are many species in the reservoir, and not all phytoplankton produce these compounds, such as 2-MIB and geosmin; $<50$ of the more than 2000 species classified to date have been directly confirmed as producers [19]. In recent years, the genes involved in the synthesis of odorants have studied a lot, and detection of odorantsproducing algae with qPCR method has been widely used [20-22]. Wang et al. have revealed genes involved in cyanobacteria and first studied the correlation between the gene (mic) and 2-MIB concentration (10-60 fg 2-MIB per mic copy) [22]. This provides a new way to identify the odorants-produced algae and must be more accurate than previous method.

Shiyan reservoir (SY) is one major water source of Shenzhen city, which is a representative water resource in hot and humid regions of China. In recent years, the reservoir has encountered seasonable $\mathrm{T} \& \mathrm{O}$ problems, especially in April to July, which is one typical high temperature and rainy season. Even one typical odorant of 2-MIB was ever detected sporadically, the key odorants, occurrence procedure and cause were not clear. In this study, by comparing to one nearby reservoir with no odor occurrence, the odor occurrence, possible odorants, odor-producing algae and possible control measures for reducing odor occurrence risk in SY reservoir were systematically investigated. The results of this study will be helpful for further improvement of the drinking water quality and water management suffering from odor problems.

\section{Methods}

\section{Field sites and sampling}

Shiyan reservoir (SY) was located at the northwest part of Shenzhen City, with a catchment area of $44 \mathrm{~km}^{2}$ and a corresponding storage capacity of 16.9 million $\mathrm{m}^{3}$. Every April to July, odor problem would occur about 4 months. For comparison, Shenzhen reservoir (SZ) was selected as reference, where no odor occurrence was recorded, with a catchment area of $60.5 \mathrm{~km}^{2}$ and a storage capacity of 45.77 million $\mathrm{m}^{3}$.

Samples were taken from the intake $(0.5 \mathrm{~m}$ below the surface) of two reservoirs from October 2016 to May 2018, and total of 66 samples were collected. Samples were collected weekly in the spring and summer (April to September), and approximately monthly at other times of the period throughout 2016 and 2018. The samples from October 28, 2016, May 8, 2017 (odor event) and September 26, 2017 were used for odorant identification analysis.

During the April to July, 2018, additional sampling sites (1-6\#) were added in SY. Sample sites 1-2\# were close to the water inlet of the reservoir and the water depth is only about 3 meters. For other sample sites, the water depth is $>10 \mathrm{~m}$. The water samples from the surface layer ( $0.5 \mathrm{~m}$ below the surface) and bottom layer 
(0.5 $\mathrm{m}$ above the sediment) were analyzed. The sampling sites of the two reservoirs are shown in Fig. 1.

While sampling, $1 \mathrm{~L}$ of water is added to $\mathrm{MgCO}_{3}$ turbid solution (prevention of pigment decomposition) for chlorophyll-a analysis, $1 \mathrm{~L}$ of water is added to $5 \%$ Lugol's iodine for algae qualification and cell counting, $1 \mathrm{~L}$ of water (no head space) is added $\mathrm{HgCl}_{2}$ solution for the odorant determination, and another $5 \mathrm{~L}$ of water was collected for qPCR analysis and other water parameters. Values of water temperature, $\mathrm{pH}$, dissolved oxygen and turbidity were obtained in situ. Water samples for odorants and other physio-chemical parameters analysis were transported to the laboratory immediately in a portable refrigerator (around $4{ }^{\circ} \mathrm{C}$ ). A total of 11 typical physio-chemical parameters were analyzed and analysis methods are shown in Table 1.
Table 1 Physio-chemical indicators and analysis methods

\begin{tabular}{ll}
\hline Indicator & Analysis methods \\
\hline Water temperature & Thermo ORION 3 STAR \\
$\mathrm{pH}$ & Thermo ORION 3 STAR \\
$\mathrm{DO}$ & HACH HQ 30d \\
Chroma & XINRUI-SD9012AB \\
Turbidity & HACH-2100AN \\
$\mathrm{UV}_{254}$ & VARIAN-CARY50 \\
DOC & GE 5310CTOC \\
$\mathrm{COD}_{\text {Mn }}$ & Acidic potassium permanganate titration \\
$\mathrm{TN}_{\mathrm{T}}$ & Alkaline potassium persulfate \\
$\mathrm{TP}$ & Molybdate spectrophotometric method \\
Chlorophyll-a & Thermal ethanol extraction spectropho- \\
& tometric method
\end{tabular}

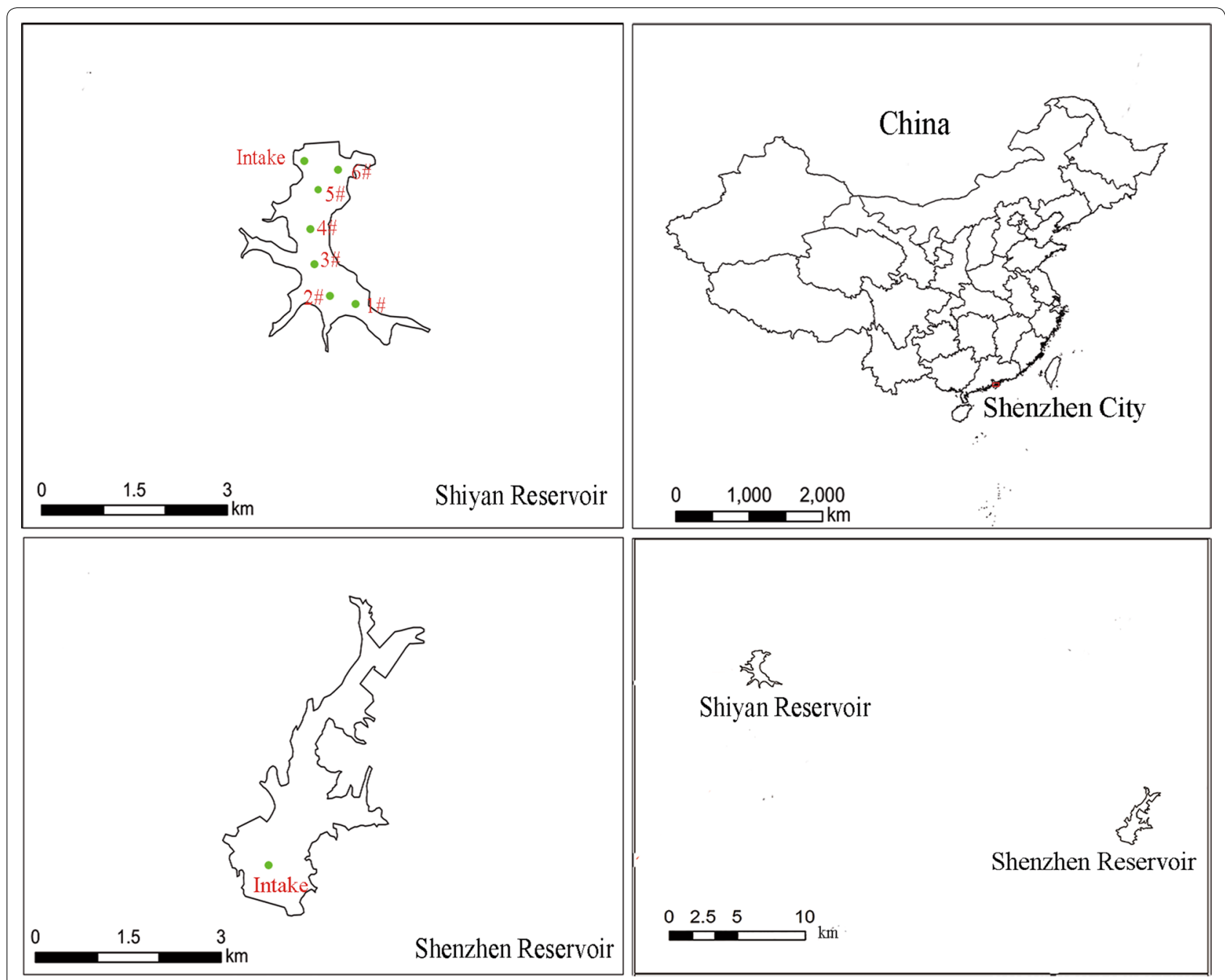

Fig. 1 The sampling sites in Shiyan reservoir and Shenzhen reservoir 


\section{Odor evaluation}

Flavor profile analysis (FPA) was employed for odor evaluation. A detailed description of the training and applications for the FPA method can be found in the standard methods for water and wastewater [23]. The panels were made up of at least four panelists for each test. Sevenpoint scales of 1-12 were used to describe the intensity of the samples [(1) odor threshold, (2)-(4) weak odor intensity, (6)-(8) moderate odor intensity, and (10)-(12) strong odor intensity]. Odor standards with different intensities were used to remind the panel of the odor descriptors and intensities with each batch of samples.

\section{OAV determination}

Odor perception in water depends not only on the concentration of odor substances, but also on the odor threshold concentration (OTC). Odor activity value (OAV), as a method of odor characterization, is defined as the ratio of odorant concentration to its threshold, which involves in the influence of odor concentration and odor threshold concentration [24]. When OAV $>1$, it means that the concentration of the compound is greater than its OTC, and has a greater contribution to the odor intensity of water. The higher the OAV is the more contribution to the odor profile [25]. While $\mathrm{OAV}<1$, it means that the concentration of the substance is lower than its OTC, and it contributes less to the odor intensity of water.

\section{GC x GC-TOFMS analysis}

The water sample was pretreated with liquid-liquid extraction. The specific steps are as follows: After the water sample was filtered through a $1.2 \mu \mathrm{m}$ glass fiber membrane (GF/C), $500 \mathrm{~mL}$ water samples were extracted using dichloromethane (HPLC grade) twice $(50 \mathrm{~mL}$ and $30 \mathrm{~mL}$ for the first and second extraction, respectively) and then dehydration was carried out with $\mathrm{Na}_{2} \mathrm{SO}_{4}$; the samples were concentrated to a final volume of $100 \mu \mathrm{L}$, followed by rotary evaporation and blowing off under a gentle nitrogen stream. The pressure of the rotary evaporation chamber was 920 mbar, while the temperatures of the water bath and cooling cycling water were $28{ }^{\circ} \mathrm{C}$ and $10{ }^{\circ} \mathrm{C}$, respectively. The overall preconcentration factor was 5000 before the analysis sample in $-20{ }^{\circ} \mathrm{C}$ stored in fridge.

Odor substances were analyzed by GC $\times$ GC-TOFMS. In the first dimension, a low polarity capillary column was used (Rxi-5silv $30 \mathrm{~m} \times 0.25 \mathrm{~mm} \times 0.25 \mu \mathrm{m}$ ), while in the second dimension column was a polar one (RXI-17 $1.79 \mathrm{~m} \times 0.1 \mathrm{~mm} \times 0.1 \mu \mathrm{m})$. Ultrapure helium $(\mathrm{He} \geqq 99.999 \%)$ was used as the carrier gas at the constant flow of $1 \mathrm{~mL} / \mathrm{min} .1 \mathrm{~mL}$ extracts were introduced using a programmed temperature vaporizing injector at $50 \mathrm{~mL} / \mathrm{s}$ in a splitless mode with the inlet temperature of $250{ }^{\circ} \mathrm{C}$. The temperature program of the first column (main GC oven) was optimized as follows: $40^{\circ} \mathrm{C}(0.2 \mathrm{~min}) \rightarrow 280^{\circ} \mathrm{C}$ (at $\left.5{ }^{\circ} \mathrm{C} / \mathrm{min}\right) \rightarrow 280{ }^{\circ} \mathrm{C}(5 \mathrm{~min})$. The temperature of the second oven was programmed from $45{ }^{\circ} \mathrm{C}(0.2 \mathrm{~min})$ to $285{ }^{\circ} \mathrm{C}$ at a rate of $5{ }^{\circ} \mathrm{C} / \mathrm{min}$ with a final hold time of $5 \mathrm{~min}$. The transfer line linking the secondary oven with the mass spectrometer was maintained at $250{ }^{\circ} \mathrm{C}$. The electron energy was $70 \mathrm{eV}$, and the detector voltage was set at $1575 \mathrm{eV}$. The data acquisition rate was 100 spectra per s, covering a mass range of $50-500 \mathrm{~m} / \mathrm{z}$. The temperature of the ion source was set at $250{ }^{\circ} \mathrm{C}$ [14] (Table 2).

\section{Algal enumeration}

The water sample was added 5\% Lugol's iodine and static settlement by $48 \mathrm{~h}$, then pre-concentrated $100 \times$ and kept in dark until cell counting [26]. The algal cell density was determined by the Utermöhl technique using a Sedgewick-Rafter counting chamber under a microscope (Nikon Eclipse 50i) with phase contrast and bright field illumination [27]. A magnification of $160 \times$ was used to enumerate the cells. Triplicates of $1 \mathrm{~mL}$ concentrated samples were collected separately and counted. The number of filamentous algal cells was calculated by dividing the measured filamentous length by the mean cell length; the number of cells in colony species such as Microcystis sp. was estimated based on colony volume and mean cell density.

\section{Real-time PCR}

The genomic DNA was extracted from Pseudanabaena sp. (FACHB1277) which is 2-MIB producer. Field samples were filtered through $0.22 \mu \mathrm{m}$ polycarbonate filter (GTTP type, Millipore, USA) and cultured algae was centrifuged for $10 \mathrm{~min}$ under $4000 \times g$ before genomic DNA extraction. The Fast DNA ${ }^{\circledR}$ SPIN KIT for Soil (MP Biomedicals, USA) kit was used and operated according to the manufacturer's instructions.

The primer pair MIB-R(f/r)(MIB-Rf 5'-CGACAGCTT CTACAYCYCCATGAC-3', MIB-Rr 5'-CGCCGCAAT CTGTAGCACCAT-3') was used to amplify the mic fragments [22]. The PCR instrument used was $\mathrm{C} 1000^{\text {TM }}$ Thermal Cycler (Bio-Rad, USA). PCR amplification was carried out in $1 \times$ DynaZyme II buffer (Thermo Scientific, USA) with $0.2 \mathrm{mM}$ of each primer, $200 \mathrm{mM}$ of dNTPs, $0.4 \mathrm{U}$ of DynaZyme II, and 20-50 ng of genomic DNA as template. The PCR protocol was $94^{\circ} \mathrm{C}$ for $3 \mathrm{~min}, 35$ cycles of $94{ }^{\circ} \mathrm{C}$ for $30 \mathrm{~s}, 59^{\circ} \mathrm{C}$ for $30 \mathrm{~s}, 72{ }^{\circ} \mathrm{C}$ for $60 \mathrm{~s}$, and $72{ }^{\circ} \mathrm{C}$ for $5 \mathrm{~min}$. Then, the amplification product is subjected to a purification operation with SanPrep KIT (Sangon Biotech, China) and performed according to the manufacturer's instructions. The size of the PCR products was checked by gel electrophoresis using a 1.5\% agarose gel 
Table 2 Information of the 54 odor compounds analyzed by GC x GC-TOFMS

\begin{tabular}{|c|c|c|c|c|}
\hline No. & Compounds & Odor description & OTC (mg/L) & CAS \\
\hline 1 & Hexanal & Herbal flavor, almond & 4.5 & $66-25-1$ \\
\hline 2 & Heptanal & Fishy & 3.0 & 111-71-7 \\
\hline 3 & Benzaldehyde & Herbal flavor & 4.5 & $100-52-7$ \\
\hline 4 & 2,4-Heptadienal & Fishy/oily & 5.0 & $4313-03-5$ \\
\hline 5 & 2-Octenal & Irritant & n.a. & $2548-87-0$ \\
\hline 6 & Nonanal & Fruity, fragrance & n.a. & 124-19-6 \\
\hline 7 & 2,6-Nonadienal & Herbal flavor/cucumber & 0.08 & $17587-33-6$ \\
\hline 8 & Decanal & Orange flavor & n.a. & $112-31-2$ \\
\hline 9 & 2,4-Decadienal & Oily & 0.029 & $2363-88-4$ \\
\hline 10 & 2,6,6-Trimethyl-1-cyclohexene-1-carboxaldehyde & Sweet, fragrance & n.a. & $432-25-7$ \\
\hline 11 & Ethylbenzene & Plastic, oily, chemical & 150.0 & $100-41-4$ \\
\hline 12 & p-Xylene & Chemical & n.a. & $106-42-3$ \\
\hline 13 & 1,4-Dichloro-benzene & Almond, sweet & 4.5 & $106-46-7$ \\
\hline 14 & 1,3,5-Trichloro-2-methoxy-benzene & Musty & 0.002 & $108-70-3$ \\
\hline 15 & Bis(2-chloroisopropyl) ether & Medicinal odor & 0.017 & $39638-32-9$ \\
\hline 16 & Butanoic acid, propyl ester & Alcohol & п.а. & $105-66-8$ \\
\hline 17 & Indole & Stinky & 0.1 & $120-72-9$ \\
\hline 18 & 3-Methyl-indole & Stinky & 1.0 & 83-34-1 \\
\hline 19 & lonone & Fragrance & 0.007 & 8013-90-9 \\
\hline 20 & Tetramethyl pyrazine & Sour, fragrance & 2.6 & $1124-11-4$ \\
\hline 21 & Pyrazine & Fragrance & 2.7 & 290-37-9 \\
\hline 22 & 2-Methoxy-3-(2-methylethyl)-pyrazine/IPMP & Musty & 0.0002 & $25773-40-4$ \\
\hline 23 & 2-Methoxy-3-(2-methylpropyl)-pyrazine/IBMP & Musty & 0.001 & 24683-00-9 \\
\hline 24 & Pyridine & Amine, stinky & 1.1 & 110-86-1 \\
\hline 25 & 2-Methyl-phenol & Medicinal odor & 14.7 & $95-48-7$ \\
\hline 26 & 4-Bromo-phenol & Medicinal odor & n.a. & $106-41-2$ \\
\hline 27 & 3-Methyl-phenol & Medicinal odor & 12.8 & $108-39-4$ \\
\hline 28 & 2-Nitro-phenol & Medicinal odor & 11.0 & $88-75-5$ \\
\hline 29 & 2,6-Dimethyl-phenol & Medicinal odor, musty & 11.0 & $576-26-1$ \\
\hline 30 & 2-Chloro-phenol & Chemical, musty, floral & 0.088 & $95-57-8$ \\
\hline 31 & Dimethyl sulfide & Rotten cabbage & 1.0 & $75-18-3$ \\
\hline 32 & Diethyl sulfide & Swampy, septic & n.a. & $352-93-2$ \\
\hline 33 & Dimethyl disulfide & Swampy, septic & 0.03 & $624-92-0$ \\
\hline 34 & Diisopropyl sulfide & Swampy, septic & n.a. & $625-80-9$ \\
\hline 35 & Propyl sulfide & Swampy, septic & 0.0019 & $111-47-7$ \\
\hline 36 & Diethyl disulfide & Swampy, septic & 0.02 & 110-81-6 \\
\hline 37 & Dimethyl trisulfide & Swampy, septic & 0.01 & $3658-80-8$ \\
\hline 38 & Butyl sulfide & Swampy, septic & 0.00189 & $544-40-1$ \\
\hline 39 & Dipropyl disulfide & Swampy, septic & n.a. & $629-19-6$ \\
\hline 40 & Amyl sulfide & Swampy, septic & 0.0011 & $872-10-6$ \\
\hline 41 & Dibutyl disulfide & Swampy, septic & n.a. & $629-45-8$ \\
\hline 42 & Dipentyl disulfide & Swampy, septic & n.a. & $112-51-6$ \\
\hline 43 & Benzyl disulfide & Foul smell & n.a. & $150-60-7$ \\
\hline 44 & 1-Pentanethiol & Rancid, stinky & n.a. & $110-66-7$ \\
\hline 45 & 1-Heptanethiol & Rancid, stinky & n.a. & 1639-09-4 \\
\hline 46 & 1-Octanethiol & Rancid, stinky & n.a. & $111-88-6$ \\
\hline 47 & 1-Nonanethiol & Rancid, stinky & n.a. & $1455-21-6$ \\
\hline 48 & Thiomorpholine & Fishy, stinky & n.a. & 123-90-0 \\
\hline 49 & Thiazole & Foul smell & n.a. & 288-47-1 \\
\hline
\end{tabular}


Table 2 (continued)

\begin{tabular}{lllll}
\hline No. & Compounds & Odor description & OTC (mg/L) & CAS \\
\hline 50 & Pentachlorothioanisole & Medicinal & n.a. & $1825-19-0$ \\
51 & Indane & Musk, fragrance & n.a. & $496-11-7$ \\
52 & Eucalyptol & Peppermint & n.a. & $470-82-6$ \\
53 & 2-Methylisoborneol & Musty & 0.01 & $2371-42-8$ \\
54 & Geosmin & Earthy & 0.004 & $19700-21-1$ \\
\hline
\end{tabular}

Table 3 FPA evaluation results of two reservoirs

\begin{tabular}{llll}
\hline Reservoir & $\mathbf{2 8 / 1 0 / 2 0 1 6}$ & $\mathbf{0 8 / 0 5 / 2 0 1 7}$ & $\mathbf{2 6 / 0 9 / 2 0 1 7}$ \\
\hline SZ & Earthy-musty (3) & Earthy-musty (3) & Earthy-musty (3) \\
& Swampy/septic (4) & Swampy/septic (3) & Swampy/septic (4) \\
SY & Earthy-musty (5) & Earthy-musty (7) & Earthy-musty (4) \\
& Grassy (6) & Grassy (7) & Grassy (3) \\
\hline
\end{tabular}

a Odor type (intensity)

and a l-HindIII/Фx-HaeII DNA marker (Thermo Scientific, USA). The concentration and purity of the product were measured with a NanoDrop ND-1000 spectrophotometer (Thermo Scientific, USA) and then used in qPCR standard curve built.

The $20 \mu \mathrm{L}$ of SYBR Green qPCR systems contained 1 $\mu \mathrm{L}$ of genomic DNA of cultured strains or environmental samples, $0.6 \mu \mathrm{M}$ of final concentration of MIB-R(f/r), $10 \mu \mathrm{L}$ of hot start reaction mix containing SYBR Green I (Gen Star, China), and $8 \mu \mathrm{L}$ of $\mathrm{ddH}_{2} \mathrm{O}$. Amplification was performed in a 7500 real-time system (ABI, USA) with the following program: an initial preheating step of $10 \mathrm{~min}$ at $95^{\circ} \mathrm{C}$, followed by 35 cycles, with one cycle consisting of $15 \mathrm{~s}$ at $95^{\circ} \mathrm{C}$ and $30 \mathrm{~s}$ at $59^{\circ} \mathrm{C}$. To determine melting temperatures for the amplification products, the temperature was raised after amplification from 70 to $95^{\circ} \mathrm{C}$, and fluorescence was continuously detected.

\section{Results and discussion}

\section{Identification of odor-caused substances}

During the odor event on May 8, 2017, a total of 43 complaints related to $\mathrm{T} \& \mathrm{O}$ problems in drinking water were received from consumers. However, the overwhelming majority $(62.79 \%, 27)$ of people could not to precise describe the odor type. This may be due to a lack of T\&O training and live in different environments [28-30]. To identify the odor type exactly, raw water samples from two reservoirs were evaluated by FPA method and the results were compared with the other two reports without odor problem (October 28, 2016 and September 26, 2017). The results are shown in Table 3 . There are weak (3-4) intensity earthy-musty and swampy/septic odor in $\mathrm{SZ}$, and no significant changes during the period of odor event on May 8, 2017. The major odor types of SY are earthy-musty and grassy, and the intensity was moderate in the odor event. Compared with usual conditions, the odor intensity of SY increased obviously (earthy-musty intensity from 5 to 7 , grassy intensity from 6 to 7 ). The main odor type in Shenzhen is earthy-musty, which is different from the previous studies on the odor and taste of fresh water source in other areas of China, for example, the septic and marshy odor in Wuxi city, and fishy odor in a north China reservoir $[4,31]$.

To determine the main odor-causing substances in the water source, 54 odorants known to cause common $\mathrm{T} \& \mathrm{O}$ problems in water sources were analyzed by $\mathrm{GC} \times \mathrm{GC}-$ TOFMS, and the results are shown in Table 4. In the two reservoirs, a variety of odor compounds were detected, 10 compounds in SZ and 12 compounds in SY. The main odor substances include earthy-musty substances (2-MIB and geosmin), swampy/septic substances (dimethyl disulfide). Before and after the odor event, there was no change in the type of odorant, but the concentration of some odorants changed. For earthy-musty substances, only geosmin was detected in the SZ. While both 2-MIB and geosmin were detected in SY, and the concentration of 2-MIB was much higher than that of geosmin (2-MIB and geosmin mean values are $36.95 \mathrm{ng} / \mathrm{L}$ and $5.54 \mathrm{ng} / \mathrm{L}$ in SY, respectively). During the odor event (May 8, 2017), the 2-MIB concentration in SY is $52.87 \mathrm{ng} / \mathrm{L}$, which is much higher than the other times $(35.85 \mathrm{ng} / \mathrm{L}$ in October 28, 2016 and $22.13 \mathrm{ng} / \mathrm{L}$ in September 26, 2017), but the geosmin concentration was unchanged and remained low.

To characterize the contribution of each compound to the odor intensity of water in a more intuitive way, we calculated the odor activity value (OAV) of each substance which was detected in the two reservoirs and the results are shown in Fig. 2. The OAVs of detected substances in SZ were almost less than 1 (only the OAV of geosmin is 1.16 in May 8, 2017), indicating that each substance contributed less to the overall odor intensity in water, which was consistent with the FPA results. Compared with SZ, a much higher OAV of 2-MIB occurred in SY, which increased significantly to 5.29 during the odor event from 3.59 and 2.21 in other two periods. This 
Table 4 GC x GC-TOFMS analysis results of two reservoirs

\begin{tabular}{|c|c|c|c|c|c|c|c|}
\hline \multirow[t]{2}{*}{ No } & \multirow[t]{2}{*}{ Compounds } & \multicolumn{2}{|c|}{ 28/10/2016 } & \multicolumn{2}{|c|}{ 08/05/2017 } & \multicolumn{2}{|c|}{$26 / 09 / 2017$} \\
\hline & & SZ & SY & $S Z$ & SY & SZ & SY \\
\hline 1 & Hexanal & n.d. & n.d. & n.d. & n.d. & n.d. & n.d. \\
\hline 2 & Heptanal & n.d. & n.d. & n.d. & n.d. & n.d. & n.d. \\
\hline 3 & Benzaldehyde & n.d. & n.d. & n.d. & n.d. & n.d. & n.d. \\
\hline 4 & 2,4-Heptadienal & n.d. & n.d. & n.d. & n.d. & n.d. & n.d. \\
\hline 5 & 2-Octenal & n.d. & n.d. & n.d. & n.d. & n.d. & n.d. \\
\hline 6 & Nonanal & n.d. & n.d. & n.d. & n.d. & n.d. & n.d. \\
\hline 7 & 2,6-Nonadienal & n.d. & n.d. & n.d. & n.d. & n.d. & n.d. \\
\hline 8 & Decanal & n.d. & n.d. & n.d. & n.d. & n.d. & n.d. \\
\hline 9 & 2,4-Decadienal & n.d. & n.d. & n.d. & n.d. & n.d. & n.d. \\
\hline 10 & 2,6,6-Trimethyl-1-cyclohexene-1-carboxaldehyde & 5.75 & 24.47 & 9.11 & 26.42 & 5.86 & 23.32 \\
\hline 11 & Ethylbenzene & n.d. & n.d. & n.d. & n.d. & n.d. & n.d. \\
\hline 12 & p-Xylene & n.d. & 6.15 & n.d. & 5.95 & n.d. & 3.21 \\
\hline 13 & 1,4-Dichloro-benzene & 1.11 & n.d. & 0.31 & n.d. & 1.32 & n.d. \\
\hline 14 & 1,3,5-Trichloro-2-methoxy-benzene & n.d. & n.d. & n.d. & n.d. & n.d. & n.d. \\
\hline 15 & Bis(2-chloroisopropyl) ether & n.d. & n.d. & n.d. & n.d. & n.d. & n.d. \\
\hline 16 & Butanoic acid, propyl ester & n.d. & n.d. & n.d. & n.d. & n.d. & n.d. \\
\hline 17 & Indole & n.d. & n.d. & n.d. & n.d. & n.d. & n.d. \\
\hline 18 & 3-Methyl-indole & n.d. & n.d. & n.d. & n.d. & n.d. & n.d. \\
\hline 19 & lonone & n.d. & n.d. & n.d. & n.d. & n.d. & n.d. \\
\hline 20 & Tetramethyl pyrazine & 1.33 & 1.18 & 1.11 & 1.23 & 1.07 & 1.54 \\
\hline 21 & Pyrazine & n.d. & n.d. & n.d. & n.d. & n.d. & n.d. \\
\hline 22 & 2-Methoxy-3-(2-methylethyl)-pyrazine/IPMP & n.d. & n.d. & n.d. & n.d. & n.d. & n.d. \\
\hline 23 & 2-Methoxy-3-(2-methylpropyl)-pyrazine/IBMP & n.d. & n.d. & n.d. & n.d. & n.d. & n.d. \\
\hline 24 & Pyridine & 33.06 & 22.95 & 45.72 & 24.63 & 37.09 & 21.89 \\
\hline 25 & 2-Methyl-phenol & 2.86 & 9.17 & 2.46 & 8.93 & 2.03 & 9.24 \\
\hline 26 & 4-Bromo-phenol & n.d. & n.d. & n.d. & n.d. & n.d. & n.d. \\
\hline 27 & 3-Methyl-phenol & 5.52 & 4.20 & 4.97 & 5.32 & 4.03 & 3.79 \\
\hline 28 & 2-Nitro-phenol & n.d. & n.d. & n.d. & n.d. & n.d. & n.d. \\
\hline 29 & 2,6-Dimethyl-phenol & n.d. & n.d. & n.d. & n.d. & n.d. & n.d. \\
\hline 30 & 2-Chloro-phenol & n.d. & n.d. & n.d. & n.d. & n.d. & n.d. \\
\hline 31 & Dimethyl sulfide & n.d. & n.d. & n.d. & n.d. & n.d. & n.d. \\
\hline 32 & Diethyl sulfide & n.d. & n.d. & n.d. & n.d. & n.d. & n.d. \\
\hline 33 & Dimethyl disulfide & 8.48 & 0.34 & 3.21 & n.d. & 6.79 & 0.56 \\
\hline 34 & Diisopropyl sulfide & n.d. & n.d. & n.d. & n.d. & n.d. & n.d. \\
\hline 35 & Propyl sulfide & n.d. & n.d. & n.d. & n.d. & n.d. & n.d. \\
\hline 36 & Diethyl disulfide & n.d. & n.d. & n.d. & n.d. & n.d. & n.d. \\
\hline 37 & Dimethyl trisulfide & n.d. & n.d. & n.d. & n.d. & n.d. & n.d. \\
\hline 38 & Butyl sulfide & n.d. & n.d. & n.d. & n.d. & n.d. & n.d. \\
\hline 39 & Dipropyl disulfide & n.d. & n.d. & n.d. & n.d. & n.d. & n.d. \\
\hline 40 & Amyl sulfide & n.d. & n.d. & n.d. & n.d. & n.d. & n.d. \\
\hline 41 & Dibutyl disulfide & n.d. & n.d. & n.d. & n.d. & n.d. & n.d. \\
\hline 42 & Dipentyl disulfide & n.d. & n.d. & n.d. & n.d. & n.d. & n.d. \\
\hline 43 & Benzyl disulfide & n.d. & n.d. & n.d. & n.d. & n.d. & n.d. \\
\hline 44 & 1-Pentanethiol & 5.58 & 6.95 & 6.73 & 7.32 & 5.65 & 7.57 \\
\hline 45 & 1-Heptanethiol & n.d. & n.d. & n.d. & n.d. & n.d. & n.d. \\
\hline 46 & 1-Octanethiol & n.d. & n.d. & n.d. & n.d. & n.d. & n.d. \\
\hline 47 & 1-Nonanethiol & n.d. & n.d. & n.d. & n.d. & n.d. & n.d. \\
\hline 48 & Thiomorpholine & n.d. & n.d. & n.d. & n.d. & n.d. & n.d. \\
\hline
\end{tabular}


Table 4 (continued)

\begin{tabular}{|c|c|c|c|c|c|c|c|}
\hline \multirow[t]{2}{*}{ No } & \multirow[t]{2}{*}{ Compounds } & \multicolumn{2}{|c|}{$28 / 10 / 2016$} & \multicolumn{2}{|c|}{$08 / 05 / 2017$} & \multicolumn{2}{|c|}{$26 / 09 / 2017$} \\
\hline & & SZ & SY & SZ & SY & SZ & SY \\
\hline 49 & Thiazole & 8.25 & 20.9 & 8.75 & 21.35 & 9.02 & 22.09 \\
\hline 50 & Pentachlorothioanisole & n.d. & n.d. & n.d. & n.d. & n.d. & n.d. \\
\hline 51 & Indane & n.d. & n.d. & n.d. & n.d. & n.d. & n.d. \\
\hline 52 & Eucalyptol & n.d. & 1.82 & n.d. & 2.01 & n.d. & 1.53 \\
\hline 53 & 2-Methylisoborneol & n.d. & 35.85 & n.d. & 52.87 & n.d. & 22.13 \\
\hline 54 & Geosmin & 2.04 & 1.65 & 4.21 & 7.98 & 1.21 & 6.99 \\
\hline
\end{tabular}
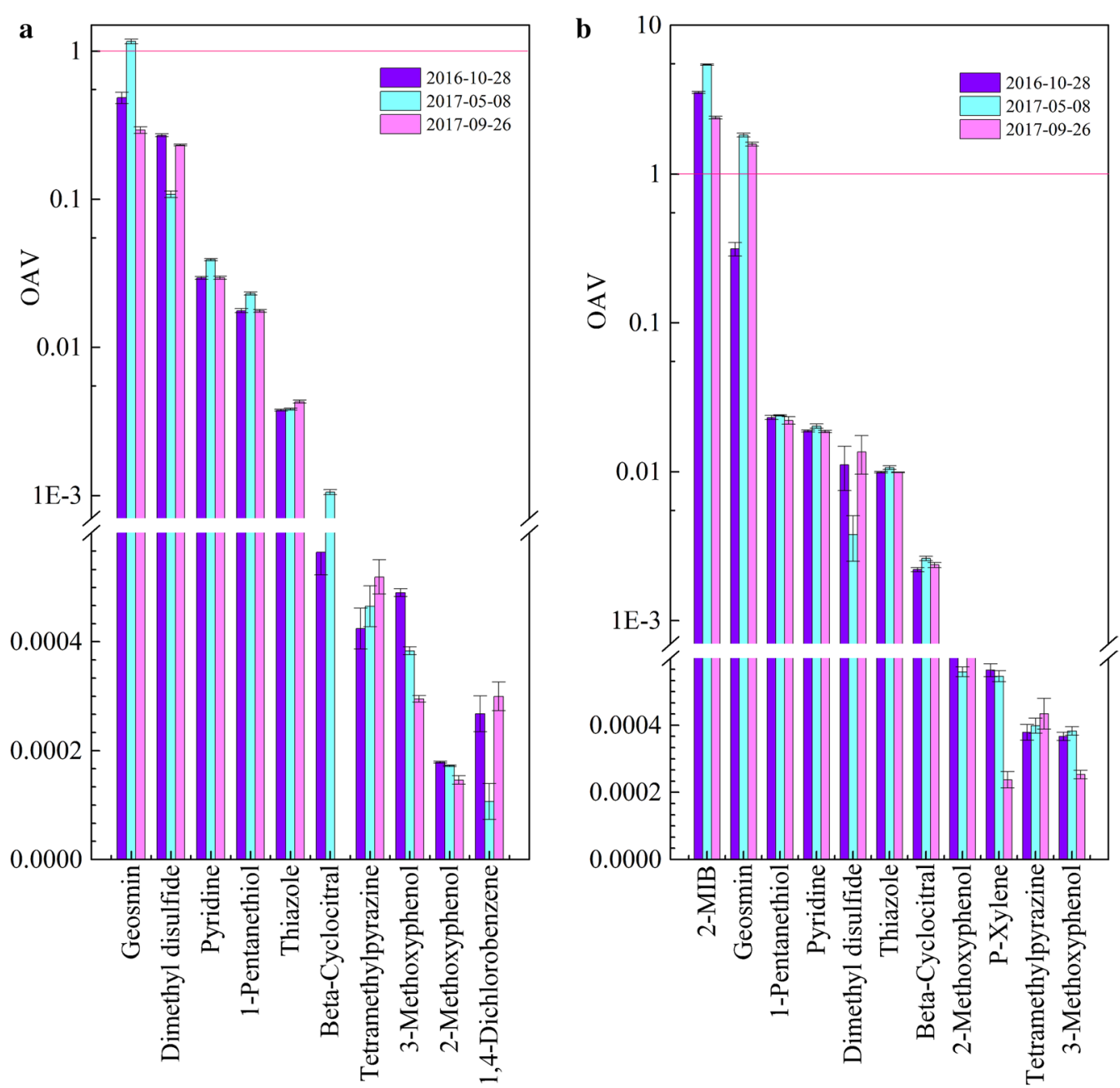

Fig. 2 OAV ranking of the detected odorants in two reservoirs: a Shenzhen reservoir, b Shiyan reservoir

implies that 2-MIB was responsible for the earthy musty problem occurrence.

The FPA result (Table 3) also shows that there is moderate odor intensity grassy smell in SY, while the GC $\times \mathrm{GC}-$ TOFMS results show that the grassy compounds were undetected in the reservoir. This may be the substances out of the list that cause the grassy odor [32-34]. There were no complaints related to grassy odor from consumers. This may be due to the fact that the weak grassy odor is easily masked by disinfectants in the finished water $[35$, 
36]. In addition, several other odor compounds such as 2,6,6-trimethyl-1-cyclohexene-1-carboxaldehyde, pyridine, 2-methyl-phenol and thiazole were detected in two reservoirs, but the OAVs of these substances are below $<1$; it means that these compounds have limited contribution to $\mathrm{T} \& \mathrm{O}$ in the reservoirs.

\section{Identification of 2-MIB-producing algae}

To identify the 2-MIB-producing algae in Shenzhen area, the phytoplankton changing of two reservoirs was detected by microscope. Five phyla, including Cyanophyta, Chlorophyta, Bacillariophyta, Euglenophyta and Cryptophyta, were detected in the two reservoirs. The total phytoplankton cell abundance in SY was much higher than SZ during the monitoring period (Additional file 1: Figure S1). The peak value of phytoplankton cells in $\mathrm{SY}$ is $272.07 \times 10^{6}$ cells $/ \mathrm{L}$, while the highest value in $\mathrm{SZ}$ is only $5.35 \times 10^{6}$ cells/L. The relative abundance of phytoplankton in SZ and SY is also different (Additional file 1: Figure S2), Cyanophyta was the dominant phylum in SY in most of the year, while the dominant phytoplankton in SZ varies significantly. Cyanophyta, Chlorophyta and Bacillariophyta form the dominant groups in different months. The main algae microscopy images of the reservoirs are shown in Additional file 1: Figure S3.

The phytoplankton data from the two reservoirs on May 8, 2017, October 28, 2016 and September 26, 2017 are shown in Fig. 3. When the odor event occurred, the total amount of algae in SY was as high as 100 million, which was significantly higher than the other two times. Although the algae counts in SZ also increased, they remained much lower than the algae level in SY. During the odor event, the relative abundance of some cyanobacteria species, especially Pseudanabaena sp., increased significantly. In previous studies, Pseudanabaena sp. has been identified as one of the 2-MIB producers in the aquatic ecosystem, and it is suggested that as little as 27-64 filaments per milliliter could impart an earthymusty odor to the water with each filament containing 30 cells $[37,38]$. Therefore, it can be inferred that 2-MIB in the reservoir was mainly produced by the Pseudanabaena sp.

The relationship between the total algae biovolume (represented by chlorophyll-a) and 2-MIB was analyzed, and the correlation was weak $(0.349, P<0.05)$ (Table 5 ). This indicates that the total algae counts cannot reflect the change of 2-MIB in the water, while correlating Pseudanabaena sp. with 2-MIB for further analysis (Additional file 1: Figure S4). The correlation coefficient was significantly higher than before $(0.766, P<0.01)$

Table 5 Correlation analysis of chlorophyll-a and 2-MIB of SY

\begin{tabular}{llll}
\hline & & Chlorophyll-a & 2-MIB \\
\hline Chlorophyll-a & Pearson correlation & 1 & $0.349^{\mathrm{a}}$ \\
& Sig. (2-tailed) & & 0.046 \\
& $\mathrm{~N}$ & 33 & 33 \\
2-MIB & Pearson correlation & $0.349^{\mathrm{a}}$ & 1 \\
& Sig. (2-tailed) & 0.046 & 33 \\
\hline
\end{tabular}

a Correlation is significant at the 0.05 level (2-tailed) 
Table 6 Correlation analysis of chlorophyll-a and 2-MIB of SY after data selected

\begin{tabular}{llll}
\hline & & Chlorophyll-a & 2-MIB \\
\hline Chlorophyll-a & Pearson correlation & 1 & $0.766^{\mathrm{a}}$ \\
& Sig. (2-tailed) & & 0.000 \\
& $\mathrm{~N}$ & 19 & 19 \\
\multirow{3}{*}{-MIB } & Pearson correlation & $0.766^{\mathrm{a}}$ & 1 \\
& Sig. (2-tailed) & 0.000 & \\
& $\mathrm{~N}$ & 19 & 19 \\
\hline
\end{tabular}

a Correlation is significant at the 0.01 level (2-tailed)

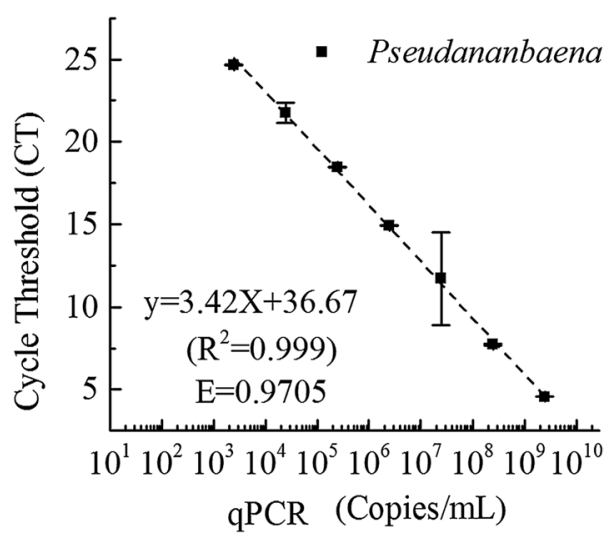

Fig. 4 Standard curve used for the qPCR assay

(Table 6). This also indicates that Pseudanabaena sp. is probably the source of 2-MIB.

The qPCR method was used to verify whether or not Pseudanabaena sp. is the 2-MIB producer in the reservoir. The genomic DNA was extracted from laboratorycultured Pseudanabaena sp. (FACHB-1277) and used as genomic DNA after amplification and purification. The gel electrophoresis result of amplification products before and after purification operation is shown in Additional file 1: Figure S5. The concentration of product after purification was determined to be $10.9 \mathrm{ng} /$ $\mu \mathrm{L}$, and the gene copy number $N$ was determined to be $4.92 \times 10^{10}$ copies $/ \mu \mathrm{L}$. Figure 4 shows that PCR standards were successfully amplified for primer MIB-R(f/r), with the range of $2.46 \times 10^{3}-2.46 \times 10^{9}$ copies $/ \mu \mathrm{L}$. The standard curve shown in the figure is linear with very high correlation $\left(R^{2}=0.999\right)$ and the high efficiency $(E=0.9705)$. This means that the amplicon quantity nearly doubled every cycle and the amplification efficiency was reasonable for quantification.

The relationship between the number of mic and 2-MIB concentration in the filed simples is shown in Fig. 5. The results indicated that the number of mic genes was closely correlated with 2-MIB concentration by linear regression $\left(R^{2}=0.746, P<0.001\right)$, and show that one

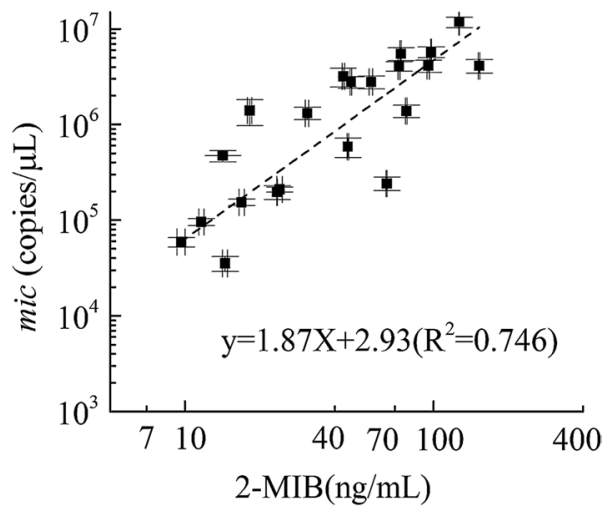

Fig. 5 Relationship between 2-MIB concentrations and Pseudanabaena sp. 2-MIB synthase gene (mic)

mic represent about $10 \mathrm{fg} 2-\mathrm{MIB}$, which is similar to previous study [22].

The quantitative detection of mic gene can reflect the formation potential of 2-MIB in DNA level and may be served as an early warning method for 2-MIB event in the reservoir. Because previous studies found that total cyanobacteria biovolume is not a consistent predictor of geosmin, and correlation between a particular taxon and particle-bound geosmin cannot be expected to occur in any instance in natural waters. This study also found a similar phenomenon in 2-MIB (Table 5). Because Pseudanabaena sp. is the main source of 2-MIB, the quantity of Pseudanabaena sp. can reflect the ability of 2-MIB production. However, algae enumeration through microscopes is time consuming and requires strong technical/professional skills. Although this qPCR method does not explain the production of 2-MIB gene expression in RNA level, compared with the observation of Pseudanabaena sp. by microscope, it is more accurate and has higher sensitivity.

\section{Possible measures to reduce 2-MIB occurrence risk}

The production of 2-MIB and geosmin by cyanobacteria can be influenced by many factors, such as temperature, light intensity, and nutritional factors $[17,39,40]$. As the Pseudanabaena sp. is the source of 2-MIB in the reservoir, it is essential to prevent the growth of Pseudanabaena sp. in order to reduce the risk of 2-MIB odor event occurrence in raw water sources. Therefore, it is imperative to assess the favorite habitat of Pseudanabaena sp. in SY. Long time monitoring of SZ and SY was conducted from October 2016 to May 2018. The temporal distribution of physio-chemical parameters is shown in Table 7.

Water temperature is an important factor to algal growth, and temperature of the two reservoirs is similar as above $18{ }^{\circ} \mathrm{C}$ all the year, and obviously higher than 
the water temperature in the northern China (about $\left.10-15{ }^{\circ} \mathrm{C}\right)[41,42]$, which is more conducive to the growth of phytoplankton. However, by comparing SZ and SY, we found that there is a difference between SZ and SY in 2-MIB and algae. The average concentration of $2-\mathrm{MIB}$ in SY is $48.06 \mathrm{ng} / \mathrm{L}$ and the peak value even more than $60 \mathrm{ng} / \mathrm{L}$, while the 2-MIB of SZ is always below its odor threshold (10 ng/L) (Additional file 1: Figure S6). In terms of algae, the algae counts in SY are also significantly higher than those in SZ, especially for Pseudanabaena sp. This means that the environmental conditions of SY are more suitable for the algae growth.

Principal compound analysis (PCA) was used to analyze the difference of physio-chemical variables in SZ and SY to find the key factors cause of the difference in phytoplankton (Fig. 6). The first two PCs explained 53.257\% of the variance together; the parameters of water temperature, $\mathrm{pH}, \mathrm{DO}$, total phosphorus (TP) and total nitrogen (TN) primarily contribute to $\mathrm{PC} 1$, while chroma, turbidity, and $\mathrm{COD}_{\mathrm{Mn}}$ primarily contribute to $\mathrm{PC} 2$.

As shown in Fig. 6, the parameters data of SY can be well separated in the direction of $\mathrm{PC} 1$, and the data derived from different season were clustered together. It indicates that the water quality of SY changes greatly with seasons. In contrast, the water parameters data of SZ cannot be well separated in the PC1 or PC2 direction, which indicates that the water quality of SZ is stable throughout the year and little fluctuation occurs therein. It is worth mentioning that $\mathrm{SY}$ and $\mathrm{SZ}$ are at similar water temperature, TP values and TN values; this shows that these factors are not limiting factors for algae growth in the SY. The two reservoirs are different in turbidity, $\mathrm{DOC}, \mathrm{COD}_{\mathrm{Mn}}, \mathrm{pH}$, chroma and $\mathrm{DO}$ which may be important factors for algae growth. However, previous studies showed that the change of $\mathrm{pH}$, chroma and $\mathrm{DO}$ is mainly caused by phytoplankton growth, so the turbidity, $\mathrm{DOC}$ and $\mathrm{COD}_{\mathrm{Mn}}$ may be the main reasons leading to the difference of the algae in the two reservoirs.

The environment around SZ and SY is quite different. $\mathrm{SZ}$ is located in the original Shenzhen Special Economic Zone (SEZ) and surrounded by East Lake park with a cleaner environment. While SY is located outside the original SEZ, there are many residential areas and industrial areas around it, and the drainage pipe network is not well designed and planned, so some sewage enters into the reservoir. This may lead to a higher $\mathrm{COD}_{\mathrm{Mn}}$ and DOC in SY. On the other hand, the raw water of Shenzhen City comes mainly from the Dongjiang River. The raw water enters SZ directly, while the raw water entering the SY must flow through the Xili reservoir and the Tiegang reservoir. The water quality may be thus affected. Therefore, strengthening the protection of SY and reducing external pollution may be one of the important means able to reduce the growth of the Pseudanabaena sp. in the reservoir.

As the concentration of 2-MIB is always at high level in SY from April to July each year, several previous odor events also occurred in this period. So additional sampling sites $(1-6 \#)$ were added during this period and the results of 2-MIB and gene mic distribution in these sites are shown in Figs. 7 and 8.

From Fig. 8, the concentration of 2-MIB varied greatly across different sites. In the surface layer of the reservoir, the concentration of 2-MIB at 4-6\# which away from the water inlet is much higher than 1-3\# close to the inlet, while the 2-MIB distribution in the bottom layer presents the opposite phenomenon. In the vertical direction, the 2-MIB concentration in surface and bottom is at same level in 1-3\#, while the 2-MIB concentration far from the inlet in the surface is higher than that on the bottom $(45.5 \pm 2.3 \mathrm{ng} / \mathrm{L}$ and $37.4 \pm 3.6 \mathrm{ng} / \mathrm{L}$, respectively). The distribution of mic genes is significantly different from 2-MIB, showing the opposite situation in 3-6\# (Fig. 8). At the 1-2\# sampling sites, the number of mic in bottom layer is basically same as that in the surface layer, which is very similar to the distribution of 2-MIB. However, at 3-6\#, the number of mic for the samples taken at the bottom layer was much higher if compared to the corresponding surface layer water samples. This may be attributed to the fact that the Pseudanabaena sp. is one typical benthic alga, which prefers to grow near the sediment to obtain enough nutrients [43]. The water parameters pertinent to the surface, and bottom, of SY are listed in Additional file 1: Table S2.

As the 1-2\# sampling sites are close to water inlet, these areas are shallow (about $3 \mathrm{~m}$ depth) and water flow is fast; the water was well mixed. This may be the main reason for the similar concentration of 2-MIB and number of mic in the surface and on the bottom. While the water depth is about $10 \mathrm{~m}$, even greater than $15 \mathrm{~m}$ at the 3-6\# sampling sites, the water qualities at these sites vary with depth which may lead to a different distribution of mic at different depths in the reservoir. It should be noted that the mic gene can only represent the potential for 2-MIB production, while the mechanism of 2-MIB synthesis of internal processes remains vague; the regulation of gene expression in RNA level may be influenced by many factors, such as light and water temperature [38]. Therefore, higher number of mic does not necessarily correlate with a higher concentration of 2-MIB. Zhang et al. [38] have suggested that increasing temperature could increase the proportion of dissolved 2-MIB in the water and the water temperature on the surface layer is higher than that at the bottom; this may promote the release of 2-MIB from the surface layer Pseudanabaena sp. During this period, 


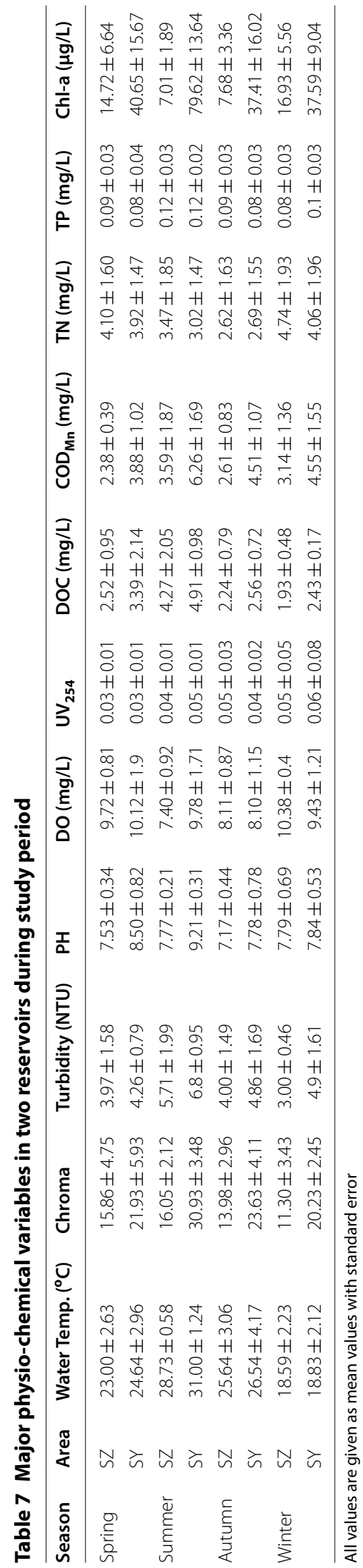




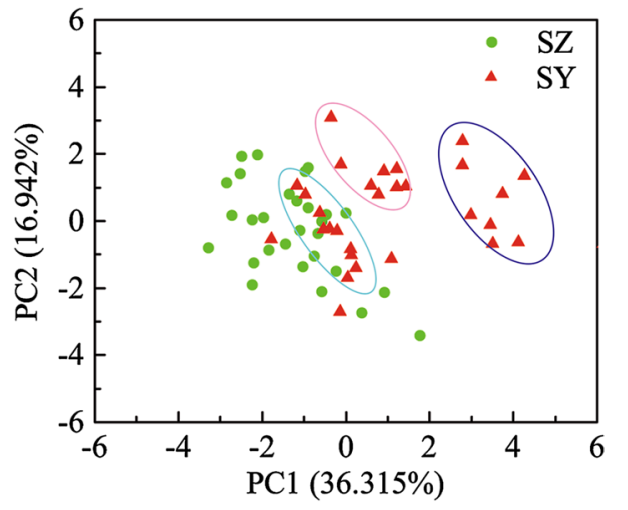

Fig. 6 PCA plot based on the physio-chemical variables in SZ and SY. The purple ellipse is mainly for July to October data, the pink ellipse is mainly for November to February data, and the blue ellipse is mainly for March to June data

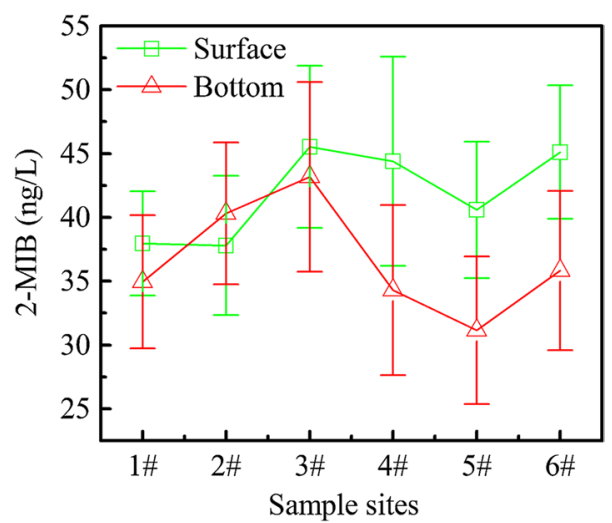

Fig. 7 2-MIB distribution in surface and bottom of different sites in SY

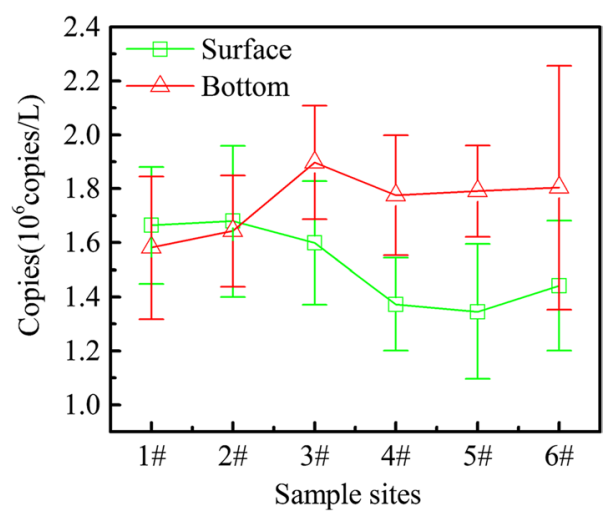

Fig. 8 mic distribution in surface and bottom of different sites in SY continuous rainfall often occurs and the concentration of 2-MIB often increased significantly on the sunny day after rain. GPP is the precursor of 2-MIB, also being the intermediate precursor of chlorophyll-a, and light plays a key role in regulating this competition $[44,45]$. When cyanobacterial cells were at light stressed conditions, the use of GPP shifted to 2-MIB synthesis. The average proportion of extracellular 2-MIB to total 2-MIB gradually increased up to $68.42 \%$ when increasing the light intensity from 10 to $85 \mu \mathrm{mol}$ photons $\mathrm{m}^{-2} \mathrm{~s}^{-1}$ [38]. Noticeably, more water would enter the reservoir during rainy season, increasing the mix of water, which might bring the Pseudanabaena sp. to the surface from the deep area. The Pseudanabaena sp. is directly exposed to strong, damaging irradiances during the sunny days, the ensuing algal cell death may cause cell rupture and decay led to intracellular 2-MIB release.

Underwater light availability is one of the most important growth factors for cyanobacteria and reduces significantly with the water level increase (about 4.2-16\% of light intensity will be reduced for each $10 \mathrm{~cm}$ water level increase in China) [18]. Some scholars proposed reducing the light intensity by changing the depth of the reservoir can control the growth of algae [42]. However, the increase of water level may also cause nutrient dilution and decrease of water temperature, which is not only inhibit the growth of algae, but also detrimental to the production and release of 2-MIB in the cell [46-48]. Therefore, the principle and actual regulation effect of this method should be studied and verified in the future.

It is worth noting that providing effective early warning for water plants is very important. There are many models to predict odor in other areas [49-51]; however, given the different environments in different regions, one warning model may not be applicable in all places. In our future work, efforts should be made to enhance the water quality monitoring of the reservoir, so as to establish accurate early warning models for better incident prediction, warning, and prevention.

\section{Conclusions}

This is the first systematic study on the T\&O problems in drinking water in Shenzhen City. An integrated approach including chemical analysis (GC $\times$ GC-TOFMS), sensory evaluation (FPA) and molecular biological method (qPCR) was employed. It is confirmed that 2-MIB is the odor-caused substance in Shiyan reservoir and Pseudanabaena sp. is the main 2-MIB producer. Compared with nitrogen and phosphorus, $\mathrm{COD}_{\mathrm{Mn}}$ and DOC had higher effects on Pseudanabaena sp. growth in Shiyan Reservoir, thus strengthening environmental protection 
around the reservoir to reduce the $\mathrm{COD}_{\mathrm{Mn}}$ and $\mathrm{DOC}$ input which might be a useful measure for controlling the growth of Pseudanabaena sp. We also demonstrated that Pseudanabaena sp. is a benthic filamentous algae; the algae growth and 2-MIB release are affected by temperature and light. The risk of sudden increase of 2-MIB will be reduced by raising the depth of water in the reservoir. Our study will improve the understanding of $\mathrm{T} \& \mathrm{O}$ problems in Shenzhen City, as well as in other hot and humid areas in China.

\section{Additional file}

Additional file 1: Figure S1. The change of total phytoplankton cell number in SZ and SY during the monitoring period. Figure S2. Relative abundance of phytoplankton in two reservoirs during the monitoring period. (a): Shenzhen Reservoir, (b): Shiyan Reservoir. Figure S3. Microscope picture of main algae in two reservoirs. (a): Pseudanabaena sp., (b): Cylindrospermopsis raciborskii, (c): Synedra, (d): Melosira granulata (Ehr.) Ralfs, (e): Cyclotella sp., (f): Cryptomonas, (g): Naviculaceae, (h): Rhizosolenia, (i): Nitzschia. Figure S4. Inter-annual variability of 2-MIB and chlorophyll-a in SY. The red triangle and the green circle represent 2-MIB and chlorophyll-a respectively, when the Pseudanabaena sp. is the dominant species. Figure S5. Agarose gel electrophoresis result of genomic DNA and PCR products before and after purification operation. (a): genomic DNA extract from FACHB1277, (b): The PCR product primed by MIB-R(f/r) before purification operation, (c): The $P C R$ product primed by MIB-R(f/r) after purification operation. Figure S6. The concentration of 2-MIB changing in SZ and SY during the monitoring period. Table S1. The different odor type solution in re-test. Table S2. The water parameters of surface and bottom in different sampling sites in SY.

\section{Abbreviations}

T\&O: taste and odor; 2-MIB: 2-methylisoborneol; GC $\times$ GC-TOFMS: comprehensive two-dimensional gas chromatography with time-of-flight mass spectrometry; FPA: flavor profile analysis; qPCR: quantitative real-time polymerase chain reaction; GC/MS: gas chromatography and mass spectrometry; OTC: odor threshold concentration; OAV: odor activity value; PCA: principal compound analysis; $\mathrm{COD}_{\mathrm{Mn}}$ : oxygen consumption; DOC: dissolved organic carbon.

\section{Authors' contributions}

CR designed the experiments, analyzed the data, and wrote the paper. $\mathrm{KY}, \mathrm{DL}$, $Y L$ and $B P$ mainly performed the odor compounds detection and flavor profile analysis (FPA). JZ and MY provide the supervision. XH and JY reviewed and edited the manuscript. All authors read and approved the final manuscript.

\section{Author details}

${ }^{1}$ Shenzhen Water Affairs (Group) Co., Ltd., Water Building, 1019 Shennan Middle Road, Futian District, Shenzhen, Guangdong, China. ${ }^{2}$ Harbin Institute of Technology Shenzhen Graduate School, HIT Campus of University Town, Nanshan District, Shenzhen, Guangdong, China. ${ }^{3}$ Civil Engineering, Guangzhou University, Wai Huan Xi Road, Guangzhou Higher Education Mega Center, Guangzhou, Guangdong, China. ${ }^{4}$ Key Laboratory of Drinking Water Science and Technology, Research Center for Eco-Environmental Sciences, Chinese Academy of Sciences, 18 Shuang Qing Road, Haidian District, Beijing, China.

\section{Acknowledgements}

The authors would like to thank Yi Tao and Lixun Zhang from the Graduate School at Shenzhen, Tsinghua University, for their support in molecular biology analysis.

\section{Competing interests}

The authors declare that they have no competing interests.
Availability of data and materials

Not applicable.

\section{Consent for publication}

Not applicable.

\section{Ethics approval and consent participate}

Not applicable.

\section{Funding}

This research was funded by Major Science and Technology Program for Water Pollution Control and Treatment (No. 2015ZX07406001), and Shenzhen Science and Technology Innovation Committee (No. GJHS20160831093405108).

\section{Publisher's Note}

Springer Nature remains neutral with regard to jurisdictional claims in published maps and institutional affiliations.

Received: 19 August 2018 Accepted: 14 November 2018

Published online: 27 November 2018

\section{References}

1. Malleret L, Dugay J, Bruchet A, Hennion M (2003) Simultaneous determination of "earthy-musty" odorous haloanisoles and their corresponding halophenols in water samples using solid-phase microextraction coupled to gas chromatography with electron-capture detection. J Chromatogr A 999(1-2):135-144

2. Burgos L, Lehmann M, Simon D, de Andrade H, de Abreu B, Nabinger DD, Grivicich I, Juliano VB, Dihl RR (2014) Agents of earthy-musty taste and odor in water: evaluation of cytotoxicity, genotoxicity and toxicogenomics. Sci Total Environ 490:679-685

3. Silva AF, Lehmann M, Dihl RR (2015) Geosmin induces genomic instability in the mammalian cell microplate-based comet assay. Environ Sci Pollut Res 22(21):17244-17248

4. Yang M, Yu J, Li Z, Guo Z, Burch M, Lin TF (2008) Taihu Lake not to blame for Wuxi's woes. Science 319(5860):158

5. Watson S (2004) Aquatic taste and odor: a primary signal of drinkingwater integrity. J Toxicol Environ Health 67(22):1779-1795

6. Suffet IHM, Khiari D, Bruchet A (1999) The drinking water taste and odor wheel for the millennium: beyond geosmin and 2-methylisoborneol. Water Sci Technol 40(6):1-13

7. Watson SB, Brownlee B, Satchwill T, Hargesheimer EE (2000) Quantitative analysis of trace levels of geosmin and MIB in source and drinking water using headspace SPME. Water Res 34(10):2818-2828

8. Chang HJ, Dietrich AM, Tanko JM (2011) Simultaneous degradation of disinfection byproducts and earthy-musty odorants by the $\mathrm{UV} / \mathrm{H}_{2} \mathrm{O}_{2}$ advanced oxidation process. Water Res 45(8):2507-2516

9. Persson F, Heinicke G, Hedberg T, Hermansson M, UhI W (2007) Removal of geosmin and MIB by biofiltration-an investigation discriminating between adsorption and biodegradation. Environ Technol 28(1):95-104

10. Lee J, Rai PK, Jeon YJ, Kim K, Kwon EE (2017) The role of algae and cyanobacteria in the production and release of odorants in water. Environ Pollut 227:252-262

11. Zhang K, Cao C, Zhou X, Zheng F, Sun Y, Cai Z, Fu J (2018) Pilot investigation on formation of 2,4,6-trichloroanisole via microbial o-methylation of 2,4,6-trichlorophenol in drinking water distribution system: an insight into microbial mechanism. Water Res 131:11-21

12. Dallüge J, Beens J, Brinkman UAT (2003) Comprehensive two-dimensional gas chromatography: a powerful and versatile analytical tool. J Chromatogr A 1000(1-2):69-108

13. Schurek J, Portoles T, Hajslova J, Riddellova K, Hernandez F (2008) Application of head-space solid-phase microextraction coupled to comprehensive two-dimensional gas chromatography-time-of-flight mass spectrometry for the determination of multiple pesticide residues in tea samples. Anal Chim Acta 611(2):163-172

14. Guo Q, Li X, Yu J, Zhang H, Zhang Y, Yang M, Lu N, Zhang D (2015) Comprehensive two-dimensional gas chromatography with time-offlight mass spectrometry for the screening of potent swampy/septic 
odor-causing compounds in two drinking water sources in China. Anal Methods 7(6):2458-2468

15. Li Z, Hobson P, An W, Burch MD, House J, Yang M (2012) Earthy odor compounds production and loss in three cyanobacterial cultures. Water Res 46(16):5165-5173

16. Wang Z, Li R (2015) Effects of light and temperature on the odor production of 2-methylisoborneol-producing Pseudanabaena sp. and geosmin-producing Anabaena ucrainica (cyanobacteria). Biochem Syst Ecol 58(3):219-226

17. Zhang T, Li L, Song L, Chen W (2009) Effects of temperature and light on the growth and geosmin production of Lyngbya kuetzingii (Cyanophyta) J Appl Phycol 21(3):279-285

18. Su M, Jia D, Yu J, Vogt RD, Wang J, An W, Yang M (2016) Reducing production of taste and odor by deep-living cyanobacteria in drinking water reservoirs by regulation of water level. Sci Total Environ 574:1477-1483

19. Association AWW (2010) Algae: source to treatment. American Water Works Association, Denver

20. Chiu Y, Yen H, Lin T (2016) An alternative method to quantify 2-MIB producing cyanobacteria in drinking water reservoirs: method development and field applications. Environ Res 151:618-627

21. Tsao HW, Michinaka A, Yen HK, Giglio S, Hobson P, Monis P, Lin TF (2014) Monitoring of geosmin producing Anabaena circinalis using quantitative PCR. Water Res 49(2):416-425

22. Wang ZJ, Song GF, Shao JH, Tan WH, Li YG, Li RH (2016) Establishment and field applications of real-time PCR methods for the quantification of potential MIB-producing cyanobacteria in aquatic systems. J Appl Phycol 28(1):325-333

23. APHA (2005) Standard methods for the examination of water and wastewater. APHA American Public Health Association, Washington, D.C

24. Burdack-Freitag A, Schieberle P (2012) Characterization of the key odorants in raw Italian hazelnuts (Corylus avellana L. Var. Tonda Romana) and roasted hazelnut paste by means of molecular sensory science. J Agric Food Chem 60(20):5057-5064

25. Pang X, Guo X, Qin Z, Yao Y, Hu X, Wu J (2012) Identification of aromaactive compounds in Jiashi muskmelon juice by GC-O-MS and OAV calculation. J Agric Food Chem 60(60):4179-4185

26. Sherr E, Sherr B (1993) Preservation and storage of samples for enumeration of heterotrophic protists. Handbook of method in aquatic microbial ecology. Lewis Publishers, Boca Raton, pp 207-212

27. Hasle GR (1978) The inverted-microscope method. Phytoplankton manual. UNESCO, Pairs, pp 88-96

28. Dalton P, Wysocki CJ (1996) The nature and duration of adaptation following long-term odor exposure. Atte Perce Psycho 58(5):781-792

29. Yu J, An W, Cao N, Yang M, Gu J, Zhang D, Lu N (2014) Quantitative method to determine the regional drinking water odorant regulation goals based on odor sensitivity distribution: illustrated using 2-MIB. J Environ Sci 26(7):1389-1394

30. Whelton AJ, Dietrich AM (2004) Relationship between intensity, concentration, and temperature for drinking water odorants. Water Res 38(6):1604-1614

31. Yan Z, Zhang Y, Yu J, Yuan H, Yang M (2011) Identification of odorous compounds in reclaimed water using FPA combined with sensory GC-MS. J Environ Sci 23(10):1600-1604

32. Cotsaris E, Bruchet A, Mallevialle J, Bursill DB (1995) The identification of odorous metabolites produced from algal monocultures. Water Sci Technol 31(11):251-258

33. Yu J, Li Z, Cao N, Yang M, Ding J, Miao T, Zhang J (2007) Analyses on cause for odor and potential problems in water source during odor episode event in Wuxi. Acta Sci Circums 27(11):1771-1777

34. Wajon JE, Alexander R, Kagi RI (1985) Determination of trace levels of dimethyl polysulphides by capillary gas chromatography. J Chromatogr A 319(2):187-194
35. Curren J, Wang ZP, Matud J, Mackey ED, Suffet M (2009) The effect of water source and chlorine and chloramine odorants in drinking water on earthy and musty odour intensity. J Water Supply: Res Technol Aqua 5(8):521-531

36. Oestman E, Schweitzer L, Tomboulian P, Corado A, Suffet IH (2004) Effects of chlorine and chloramines on earthy and musty odors in drinking water. Water Sci Technol 49(9):153-159

37. Huang X, Huang Z, Chen X, Zhang D, Zhou J, Wang X, Gao N (2018) The predominant phytoplankton of Pseudanabaena holding specific biosynthesis gene-derived occurrence of 2-MIB in a drinking water reservoir. Environ Sci Pollut Res 25:0944-1344

38. Zhang T, Zheng L, Li L, Song L (2016) 2-Methylisoborneol production characteristics of pseudanabaena sp. FACHB 1277 isolated from Xionghe reservoir, China. J Appl Phycol 28(6):3353-3362

39. Saadoun IM, Schrader KK, Blevins WT (2001) Environmental and nutritional factors affecting geosmin synthesis by Anabaena sp. Water Res 35(5):1209-1218

40. Havens KE, James RT, East TL, Smith VH (2003) N:P ratios, light limitation, and cyanobacterial dominance in a subtropical lake impacted by nonpoint source nutrient pollution. Environ Pollut 122(3):379-390

41. Chen J, Xie P, Ma Z, Niu Y, Tao M, Deng X, Wang Q (2010) A systematic study on spatial and seasonal patterns of eight taste and odor compounds with relation to various biotic and abiotic parameters in Gonghu Bay of Lake Taihu, China. Sci Total Environ 409(2):314-325

42. Su M, Yu J, Zhang J, Chen H, An W, Vogt RD, Andersen T, Jia D, Wang J, Yang M (2015) MIB-producing cyanobacteria (Planktothrix sp.) in a drinking water reservoir: distribution and odor producing potential. Water Res 68:444-453

43. Liu J, Vyverma W (2015) Differences in nutrient uptake capacity of the benthic filamentous algae Cladophora sp., Klebsormidium sp. and Pseudanabaena sp. under varying N/P conditions. Bioresour Technol 179(2015):234-242

44. Zimba PV, Dionigi CP, Millie DF (1999) Evaluating the relationship between photopigment synthesis and 2-methylisoborneol accumulation in cyanobacteria. J Phycol 35(6):1422-1429

45. Zhang T, Li D, Li J (2012) Biosynthesis of geosmin and 2-methylisoborneol in the prokaryotes - a review. Acta Microbiol Sin 52(2):152-159

46. Wood S, Williams ST, White WR (2001) Microbes as a source of earthy flavours in potable water-a review. Int Biodeterior Biodegrad 48(1-4):26-40

47. Izaguirre G, Taylor WD (2004) A guide to geosmin- and MIB-producing cyanobacteria in the United States. Water Sci Technol 49(9):19-24

48. Halstvedt CB, Rohrlack T, Andersen T, Skulberg O, Edvardsen B (2007) Seasonal dynamics and depth distribution of Planktothrix spp. in Lake Steinsfjorden (Norway) related to environmental factors. J Plankton Res 29(5):471-482

49. Dzialowski AR, Smith VH, Huggins DG, deNoyelles F, Lim N, Baker DS, Beury JH (2009) Development of predictive models for geosmin-related taste and odor in Kansas, USA, drinking water reservoirs. Water Res 43(11):2829-2840

50. Kehoe MJ, Chun KP, Baulch M (2015) Who smells? Forecasting taste and odor in a drinking water reservoir. Environ Sci Technol 49(18):10984-10992

51. Qi M, Chen J, Sun X, Deng X, Niu Y, Xie P (2012) Development of models for predicting the predominant taste and odor compounds in Taihu Lake, China. PLoS ONE 7(12):e51976 